\title{
UN LARGO E INCONCLUSO CAMINO HACIA LA IGUALDAD SUSTANCIAL Y LA NECESIDAD DE ENFOQUE DE GÉNERO EN LAS POLÍTICAS PÚBLICAS
}

\author{
A LONG AND UNFINISHED PATH TOWARDS SUBSTANTIAL EQUALITY \\ AND THE NEED FOR A GENDER APPROACH IN PUBLIC POLICIES
}

\author{
Gaudy Yely Veliz Mayta* \\ Investigadora independiente \\ Lima-Perú \\ http:/ / orcid.org/0000-0003-0021-7704 \\ gauddy_v@yahoo.com
}

\section{Resumen}

Siendo que la mayor incursión de la mujer al mercado laboral y educación ha conllevado cambios en la sociedad, estos no se traducen en mejores condiciones para ellas; por ello la necesidad del enfoque de género que permita diseñar políticas sociales inclusivas, que comprendan la heterogeneidad de este colectivo e involucren al hombre como parte del problema. Es así, que en primer orden se aborda la historia respecto a la conquista de derechos de las mujeres que lamentablemente han sido más formales que sustanciales. En segundo término, se aborda como los estereotipos de género han perpetuado situaciones de inequidad, por ello la necesidad del enfoque de género como instrumento de análisis. En tercer término, la necesidad de políticas públicas sociales con enfoque de género que permitan redefinir espacios, mayor equidad, igualdad sustancial que permita el disfrute de derechos de las mujeres y mayor participación de la mujer en la toma de decisiones.

Palabras claves: Estereotipos de género, enfoque de género, políticas sociales, igualdad sustancial.

\section{Abstract}

Being that incursion of women into the labor market and education has led to changes, these do not translate into better conditions; Therefore, the need for a gender approach that allows the design of inclusive social policies that involve men as part of the problem. Thus, in the first order the history regarding the conquest

Fiscal Adjunta Superior Civil y Familia Distrito Fiscal de Lima Este. Candidata a Magister en Derecho Civil con mención en Derecho de Familia por la Universidad Femenina del Sagrado Corazón. Egresada de Doctorado en Derecho por Universidad San Martín de Porres. 
of women's rights is addressed, which unfortunately have been more formal than substantial. Second, it addresses how gender stereotypes have perpetuated situations of inequity, hence the need for a gender approach as an instrument of analysis. Third, the need for social public policies with a gender approach that allow redefining spaces, greater equity, equality, substances that allow the enjoyment of women's rights and greater participation of women in decision-making.

Key words: Gender stereotypes, gender focus, social policies, care policies.

\section{INTRODUCCIÓN}

El proceso de conquista de derechos de las mujeres a lo largo de la historia no ha sido fácil; y aún persiste las asimetrías de poder y vulneración de derechos; como consecuencias de estereotipos de género que directa o indirectamente se han plasmado en leyes y políticas públicas que refuerzan estos patrones. Si bien la incursión de la mujer al mercado laboral y educativo ha conllevado cambios, ello no se traduce en mejores condiciones para ellas; por ello la necesidad del enfoque de género que permita diseñar políticas sociales inclusivas, que involucren al hombre como parte del problema y no lo excluyan. Es así, que en primer orden se aborda la historia respecto a la conquista de derechos de las mujeres que lamentablemente han sido más formales que reales. En segundo término, se aborda como los estereotipos de género han perpetuado situaciones de inequidad en mujeres y hombres, estereotipos que se plasman en leyes e incluso en las decisiones judiciales; sin embargo, no solo afectan a las mujeres sino también a los hombres; no obstante, el mayor impacto ha sido y sigue siendo en las mujeres, pero dentro de este grupo el impacto es diferenciado. Por ello, la necesidad de una mirada más realista a las verdaderas necesidades de este colectivo que tome en cuenta que se trata de un colectivo no homogéneo, dónde las oportunidades no han sido iguales para todas; a ello el impacto de su incursión en el mercado laboral -formal e informal- ha conllevado a nuevas realidades, como el caso de las mujeres trabajadoras cabeza de hogar con mayor grado de vulnerabilidad, situación que demanda respuestas del Estado a través de políticas sociales con enfoque de género que incentiven su independencia económica pero que se enfoquen también en políticas de cuidado que involucren a los hombres. Finalmente, la necesidad de que estas políticas sociales sean diseñadas con enfoque de género, multisectoriales y factores inter seccionales, que impacten no solo en el ámbito laboral, sino que también se diseñen intervenciones de cuidados universales -oferta de cuidados- y fomento del involucramiento del hombre en las labores del hogar, mayor participación en espacios políticos y sociales de toma 
de decisiones, que no se enfoquen solo en la mujer como si ella fuera el problema sino que incluyan también al hombre, pues estas inequidades afectan a hombres y mujeres, aunque con mayor impacto en el colectivo mujeres, así abordamos el presente trabajo.

\section{UN ARDUO CAMINO HACIA LA CONQUISTA Y REIVINDICACIÓN DE DERECHO}

Las mujeres a lo largo de la historia han tenido un tratamiento discriminatorio, de imposición de roles y subordinación hacia la figura masculina. Basta un repaso por la historia y verificar que durante el siglo XV y XVI era un ser invisible, asignándoles roles del ámbito doméstico con fines reproductivos y de cuidado, supeditada a la autoridad del hombre, considerada casi como una cosa, negándoles los mínimos derechos: igualdad, ejercer libertad, educación, decidir sobre su vida y cuerpo. Así pues, se trataba de una época en la que no se le reconocía ciudadanía alguna, no podía decidir sobre su proyecto de vida ni ejercer sus derechos, desconociendo su dignidad consustancial a la esencia humana.

Sin embargo, pese a esas circunstancias difíciles, siempre hubo voces de mujeres que han luchado de manera constante en este largo e inconcluso camino de reivindicación de derechos, igualdad en sentido material, democratización de roles y espacios por una sociedad justa donde el ser humano valga lo mismo, pues su condición de humanidad se basa en la dignidad que no está supeditada a títulos nobiliarios, patrimonio, sexo; roles; por el contrario, es consustancial a la naturaleza humana.

Así pues en la Edad Media, la situación de la mujer si bien era ligada al ámbito privado-doméstico; el impacto no era el mismo dentro de este colectivo; como refiere Duarte García (2016) las mujeres de la nobleza tenían cierta consideración para acceder a la educación, vinculada a la preparación para ser una buena ama de casa y esposa; así eran obligadas a casarse con fines de alianzas previa transmisión de dote; dote que no podían administrar así enviudaran. Sin embargo, en el caso de las mujeres de estratos más deprimidos, la situación era más difícil, dedicadas a la servidumbre o esclavizadas sin ningún tipo de acceso a la educación. No obstante, surge un grupo de mujeres que osaban actuar contra ese orden impuesto, aquellas denominadas brujas, encasilladas en roles maléficos, pero que en realidad tenían habilidades ya sea para la cura mediante la preparación de brebajes naturales, atendían partos, poseían sabiduría en áreas diversas. En este sentido, este grupo de mujeres cuyas conductas se consideraban contrarias al orden establecido implicaban una amenaza a 
ese orden que creían natural; por ello fueron perseguidas y estereotipadas, pues se consideraba que solo los hombres estaban legitimados para acceder al conocimiento y educación.

En este contexto, en el siglo XV resalta el rol de una mujer adelantada a la época, quien con sus ideas cuestionaba la sociedad discriminatoria de ese entonces, quien utilizaba sus escritos como vehículo para alzar su voz reclamando mejores derechos para la mujer como el acceso a la educación, se trata, Christine de Pizan, poeta y erudita de la época, quien cuestiona la imposición de roles, el poder autoritario del patriarcado, reclamando el derecho a la educación de la mujer. Sus publicaciones ocasionaron un revuelo para dicha época, una de sus obras con mayor difusión fue La ciudad de las damas.

Durante el siglo XVIII, edad de las luces - ilustración, estas voces se dan con mayor énfasis; siendo la literatura un vehículo a través del cual las mujeres visibilizan esa situación de inequidad, como es el caso de Olympe de Gouges que en 1789 escribe la famosa Declaración de los Derechos de la Mujer y Ciudadanía; "la narrativa y la novela se erigió como el lugar, eminentemente privado en su origen pero con aspiraciones públicas, en donde las mujeres comenzaron a desarrollar un programa de desafío a la división de dichas esferas; por ejemplo: Virginia Wolf y Simone de Beauvoir (...)" (Rábago, 2008, p.10). En fin, la lista de mujeres que alzaron sus voces de protesta contra la inequidad del sistema sería extensa de nombrar; no obstante, las voces individuales sin ser respaldadas por movimientos de apoyo no generan grandes cambios.

Sin embargo, no solo las mujeres cuestionaban esta situación de inequidad, sino también, surgen pensadores que van en la misma línea como François Poulain de la Barre quien también alzaba su voz de protesta ante una situación de inequidad y negación de acceso a la educación a las mujeres, se pronunciaba en contra de la educación elitista y selectiva solo para los hombres.

A ello, el surgimiento de la etapa industrial conlleva cambios que respondían a la inclusión de la mujer en el ámbito económico-laboral lo cual produce un punto de inflexión en la sociedad, visibilizando las injusticias de la división sexual del trabajo basado en estereotipos de género, la violencia doméstica; las diferencias de trato e inequidad hacia la mujer en el ámbito laboral pues percibían un menor salario por el mismo trabajo o la jornada laboral ejercido por un hombre. En estas circunstancias, destacan los movimientos obreros liderados por mujeres, 
emergiendo movimientos de mujeres con un objetivo común: ejercer derechos en condiciones de igualdad.

Fue en el siglo XX, 1910, que se realiza la II Conferencia Internacional de Mujeres Socialistas realizada en Copenhague donde nuevamente se aborda el tema de los derechos laborales femeninos, igualdad de derechos y el derecho al voto. Pero sin duda un hito en la conquista de derechos fue la dación de la Convención sobre la Eliminación de todas las Formas de Discriminación contra la Mujer, CEDAW, así la Comunidad Internacional logra un consenso en la necesidad de protección de este colectivo, adoptando en diciembre de 1979 por Resolución 34/180 de la Asamblea General de las Naciones Unidas dicho acuerdo convencional. En dicho instrumento internacional se establecen obligaciones de los Estados y estándares mínimos de protección y garantía de derechos. Sin embargo, debe advertirse que en este instrumento internacional no se habla expresamente de violencia sino de discriminación.

Así, en su artículo $1^{\circ}$ define como discriminación: "toda distinción, exclusión o restricción basada en el sexo que tenga por objeto o por resultado menoscabar o anular el reconocimiento, goce o ejercicio por la mujer, independientemente de su estado civil, sobre la base de la igualdad del hombre y la mujer, de los derechos humanos y las libertades fundamentales en las esferas política, económica, social, cultural y civil o en cualquier otra esfera" (Convención sobre la Eliminación de todas las Formas de Discriminación contra la Mujer [CEDAW],1979, art.1). Años más tarde, la Recomendación General 19 complementa el concepto de discriminación incluyendo como una forma de discriminación a la violencia de género que implica un cambio de visión y mayor ámbito de protección.

Posteriormente, en 1994, a nivel regional por consenso de los Estados, emerge la Convención Interamericana para Prevenir, Sancionar y Erradicar la Violencia contra la Mujer debiendo resaltarse que es en este instrumento convencional que por primera vez se habla de violencia contra la mujer de manera expresa; ampliando el ámbito de protección al precisarse que la violencia puede perpetrase en el ámbito familiar y unidad doméstica, en la comunidad ó ser ejercida o tolerada por el Estado; así pues, el ámbito familiar ya no es considerado como un espacio privado donde el Estado no debe intervenir.

Así de manera diáfana se establece: "Para los efectos de esta Convención debe entenderse por violencia contra la mujer cualquier acción o conducta, basada en su género, que cause muerte, daño o sufrimiento 
físico, sexual o psicológico a la mujer, tanto en el ámbito público como en el privado" (Convención Interamericana para Prevenir, Sancionar y Erradicar la Violencia contra la Mujer,1994, artículo 1). Son estos instrumentos convencionales que inician una nueva etapa de respeto y garantía de derechos de las mujeres, que demanda de los Estados no solo armonizar su legislación a estos estándares mínimos sino también adoptar acciones concretas para lograr la igualdad de oportunidades como las acciones afirmativas.

Debe enfatizarse que, la CEDAW se refería expresamente a la discriminación contra la mujer; sin embargo, con la recomendación General $N^{\circ} 19$, se amplía el contenido y establece como debe interpretarse el artículo $1^{\circ}$ de la convención citada, incluyendo como una forma de discriminación la violencia contra la mujer; "En el artículo 1 de la Convención se define la discriminación contra la mujer. En la definición de la discriminación se incluye la violencia basada en el sexo, es decir, la violencia dirigida contra la mujer porque es mujer o que la afecta en forma desproporcionada (...) La violencia contra la mujer puede contravenir disposiciones concretas de la Convención, independientemente de que en ellas se mencione expresamente a la violencia o no" ; así pues se entiende que la violencia es una forma de discriminación, y con la dación de la Convención Interamericana para Prevenir, Sancionar y Erradicar la Violencia contra la Mujer, se específica y se clarifica la violencia por razón de género.

No se puede dejar de mencionar en este largo proceso aún inconcluso, la Conferencia Copenhague y Nairobi, escenarios en que se visibiliza la necesidad de políticas claras que permitan la tan ansiada igualdad de oportunidades en el ámbito económico, social, cultural, político y jurídico, cuyo mayor énfasis se plasma durante la Cuarta Conferencia Mundial sobre la Mujer, celebrada en Beijing el año 1995,escenario en el que se establece la necesidad de una especial protección a los derechos humanos de las mujeres, y en tal sentido los Estados deben adoptar las medidas que garanticen esos derechos, constituyendo uno de los Objetivos de Desarrollo Sostenible (ODS) orientado al empoderamiento de las mujeres en un escenario de igualdad material.

Sin embargo, pese a los avances aún existen retos pendientes, reivindicaciones que necesitan ser visibles y que respondan a las necesidades de las mujeres en su heterogeneidad, a las diversas realidades que las mujeres atraviesan en su ciclo de vida, cuyas necesidades son diferentes en los diversos contextos y culturas, situación que demanda por parte de los Estados nuevos retos que respondan a las realidades cambiantes. 
A esta situación, nose puede dejar deadvertir los preocupantes índices de violencia de género contra la mujer no solo dentro del ámbito familiar, sino también en el público; y que en gran medida obedecen a concepciones equivocadas de las familias y comunidad, basada en imposición de roles que responden a construcciones sociales y culturales equivocadas; situaciones que en ocasiones son reforzadas con intervenciones del Estado a través de políticas públicas, estrategias o planes, que en principio son neutras pero cuyos efectos son adversos al colectivo mujeres; es por ello, la importancia y necesidad de un enfoque de género en el diseño de estas.

El ser mujer en una sociedad basada en estereotipos de género que solo incentivan la inequidad, expone a la mujer a situaciones de mayor vulnerabilidad y desafíos constantes, pues a lo largo de su vida se enfrenta no solo a contexto de violencia sino también a disyuntivas constantes que no le permiten un ejercicio pleno de sus derechos: vida sin violencia, desarrollo profesional, derecho a la salud y derechos reproductivos, educación, entre otros.

En este último aspecto, la mayor incursión de la mujer en el mercado laboral, acceso a la educación, ha impactado en las formas de relacionarse incrementado los índices de mujeres solteras con carga familiar ( familias monoparentales) y mujeres trabajadoras solteras; sin embargo, las familias monoparentales de estratos socioeconómicos deprimidos a cargo de mujeres presentan mayor vulnerabilidad, por ello, exige del Estado políticas sociales que respondan a esta situación y eviten no solo perpetrar estereotipos de género, sino violencia y pobreza; se necesita una visión que comprenda esta nueva realidad y a partir de esa comprensión se diseñe intervenciones (políticas intersectoriales) que a largo plazo permitan responder a estas necesidades y garanticen la plena vigencia de los derechos de las mujeres en las diversas etapas de sus vidas, aspectos que se desarrollará en los siguientes ítems.

\section{ESTEREOTIPOS DE GÉNERO, QUÉ ES LO QUE DEFINE SER MUJER Y LA NECESIDAD DE UN ENFOQUE DE GÉNERO.}

Como se ha precisado, a lo largo de la historia la mujer siempre ha tenido un trato discriminatorio, de negación de derechos, siendo víctima de violencia no solo en el ámbito familiar y social sino también violencia institucionalizada por parte del Estado. Estado que expide leyes, diseña políticas públicas que no necesariamente responden a las necesidades de las mujeres en su diversidad, y que muchas veces una intervención mal enfocada puede generar efectos adversos a los esperados, pues las políticas 
públicas y sociales pueden partir de una medida neutra pero que en los hechos puede generar efectos adversos, lo que en doctrina se denomina discriminación indirecta, discriminación que es más complicada de detectar en contraposición a la discriminación directa.

Ello lleva a plantear la importancia de diferenciar sexo, género y el enfoque de género como categorías diferenciadas a efecto de poder entender la problemática de estas situaciones de inequidad, y evitar asimilar el enfoque de género como instrumento de análisis aplicado solo en el caso de mujeres.

Por ello y en primer orden, debemos preguntarnos qué concepto tenemos de los que es ser mujer y ser hombre, si bien se parte de una diferencia biológica en base al sexo que diferencia al hombre y a la mujer, es una diferencia objetiva; pero ello no implica adscribir determinadas conductas ; así, "el término sexo se refiere a la diferenciación biológica y orgánica entre hombres y mujeres, mientras que la expresión género se refiere (...) a una construcción simbólica que incluye el conjunto de roles y atributos socioculturales asignados a una persona a partir del sexo al que pertenece, convirtiendo la diferencia sexual en diferencia cultural"(Carmona, 2018, p.312). Y es esta construcción de roles, en base a la diferencia sexual (biológica) conlleva a la definición de lo masculino y femenino, y que históricamente ha originado una desvalorización de lo femenino, la cosificación de la mujer, bajo ideas predominantemente machistas; estas se refuerzan con el tiempo y se transmiten de generación en generación, normalizando conductas y comportamientos, impartiendo roles al hombre y a la mujer bajo la creencia de que "así debe ser" desconociendo la valía del ser humano y los espacios de libertad para la realización de sus derechos.

Esta normalización ocasiona que muchas mujeres por la falta de oportunidades normalicen su situación de privación de derechos y oportunidades, como el derecho a la educación, derechos reproductivos, entre otros, y que el hombre tenga una visión de la mujer con función reproductiva y de cuidado del hogar, y en otros casos les exige un doble esfuerzo y desafíos constantes para poder ejercer sus derechos.

Son estas concepciones culturales-sociales que asigna a la mujer ciertas características y roles vinculados al ámbito de la familia: mujer cuidadora, roles de madre, ser frágil, sensible asignándoles el ámbito privado como el espacio natural en el cual debe desarrollarse y transitar, estos estereotipos son tan enraizados en la sociedad, a tal punto de creerse que la realización de la mujer se da con la maternidad o con el matrimonio, olvidando que esta es una decisión única y exclusiva de la mujer, y si en su proyecto de 
vida decidió no procrear, dicha decisión no la descalifica; sin embargo, esta exigencia no se da con el mismo rigor en el caso de los hombres.

En contraposición a ello, el hombre según estás concepciones no debería demostrar emociones porque se asocia a debilidad, el hombre debe ser fuerte, hombre proveedor, con carácter, a quien se le permite desenvolverse en el espacio público quien no debería ocuparse de las tareas domésticas, estas ideas preconcebidas impiden que el hombre pueda expresar emociones con libertad pues las reglas sociales se imponen. Como refiere Cook y Cusak:"Los estereotipos de género se refiere a la construcción social y cultural de hombres y mujeres, en razón de sus diferentes funciones físicas, biológicas, sexuales y sociales ... refiere a un grupo estructurado de creencias sobre los atributos personales de mujeres y varones (1997, p. 23); así se enfatiza que estos roles impuestos en base a la construcción de una idea de género impone moldes que deben ser cumplidos, estandarizando comportamientos, conductas, como aceptables o no aceptables dentro de un orden social en base a la idea de lo que es adecuadamente masculino o femenino.

Bajo estas concepciones sociales culturales se asignan roles en la familia, espacios, formas de relacionarse, surgiendo la clásica división sexual del trabajo, hoy cuestionada, pues responde a una lógica patriarcal que sigue generando factores de subordinación y dependencia económica. Así, para Noguera "la propiedad estuvo vinculada con el surgimiento de la esfera pública y sus protagonistas; explica que la llave para dicho ingreso estaba vinculado con la propiedad asimilada al hombre; por ende, las mujeres quedaban excluidas al carecer de propiedad alguna; así las mujeres quedaban relegadas al ámbito privado doméstico. Sin embargo, en ambos espacios se ejerce trabajo, solo que en este último el trabajo no es valorado."(s/f) Así pues, el trabajo doméstico es considerado como un rol natural de la mujer, una contribución al hogar pero no se considera la valorización del mismo; y como bien precisa Rábago " La ausencia de miradas en el espacio doméstico también implica la ausencia de reconocimiento y , de ahí, las dificultades de participación política para las mujeres .Al permanecer la esfera privada en aséptica a la política, también el trabajo que ocurría en dicha esfera quedó oculto y en gran medida subsumido dentro de la venta del trabajo de los varones en la esfera pública" ( 2008, p.4).; esta situación de desvalorización , de dependencia económica refuerza las asimetrías de poder.

Son estas concepciones distorsionadas las que han ocasionado acciones de desvalorización a la mujer que se evidencian en diversos escenarios; y el Derecho no ha sido ajeno a ello, pues en varios cuerpos legales se plasma la lógica machista que han reforzado estas construcciones y estereotipos, 
evidenciándose en la dación de instrumentos normativos pero también en su aplicación, "Los estereotipos distorsionan las percepciones y dan lugar a decisiones basadas en creencias preconcebidas y mitos, en lugar de hechos. Con frecuencia, los jueces adoptan normas rígidas sobre lo que consideran un comportamiento apropiado de la mujer y castigan a las que no se ajustan a esos estereotipos" (Comité para la eliminación de la discriminación contra la mujer [Comité CEDAW] Recomendación General N³3, 2015, numeral 26).

En este sentido, CEDAW, en su artículo 1, define como discriminación: “toda distinción, exclusión o restricción basada en el sexo que tenga por objeto o por resultado menoscabar o anular el reconocimiento, goce o ejercicio por la mujer, independientemente de su estado civil, sobre la base de la igualdad del hombre y la mujer, de los derechos humanos y las libertades fundamentales en las esferas política, económica, social, cultural y civil o en cualquier otra esfera" (CEDAW, 1979,artículo 1). Dicho marco normativo para efectos de una mejor aplicación debe ser complementado con la Recomendación General N³5, que establece el concepto de violencia de género, actualizando a la Recomendación General 19, así se establece: "violencia por razón de género contra la mujer" se utiliza como un término más preciso que pone de manifiesto las causas y los efectos relacionados con el género de la violencia. La expresión refuerza aún más la noción de la violencia como problema social más que individual, que exige respuestas integrales, más allá de aquellas relativas a sucesos concretos, autores y víctimas y supervivientes" (Comité CEDAW, Recomendación General N 35, 2017, numeral 9)

Por su parte, la Recomendación General $N^{\circ} 28$ se orienta a dar contenido al artículo $2^{\circ}$ de la Convención, relacionado a las obligaciones que se imponen a los Estados en su deber de respetar, proteger y hace cumplir los derechos de las mujeres en un ámbito de igualdad sustancial. Así, se establece:

Según el artículo 2, los Estados partes deben ocuparse de todos los aspectos de sus obligaciones jurídicas en virtud de la Convención para respetar, proteger y hacer cumplir el derecho de la mujer a la no discriminación y al goce de la igualdad. La obligación de respetar requiere que los Estados partes se abstengan de elaborar leyes, políticas, normas, programas, procedimientos administrativos y estructuras institucionales que directa o indirectamente priven a la mujer del goce de sus derechos civiles, políticos, económicos, sociales y culturales en pie de igualdad con el hombre. La obligación de proteger requiere que los Estados partes protejan a la mujer contra la discriminación por parte de actores privados y adopten medidas directamente orientadas 
a eliminar las prácticas consuetudinarias y de cualquier otra índole que alimenten los prejuicios y perpetúen la noción de inferioridad o superioridad de cualquiera de los sexos y los roles estereotipados de los hombres y las mujeres. La obligación de cumplir requiere que los Estados partes adopten una amplia gama de medidas para asegurar que la mujer y el hombre gocen de jure y de facto de los mismos derechos, incluida, cuando proceda, la adopción de medidas especiales de carácter temporal ...(Comité Cedaw, 2010, numeral 9)

Y es justamente, el escenario de convencionalidad, marco universal y regional, que ha permitido a través del control de convencionalidad evidenciar cómo los estereotipos de género impactan de manera negativa en las formas de relacionarse tanto en hombres como mujeres; sin embargo, causan mayor perjuicio en el colectivo mujeres.

Un caso emblemático a nivel de nuestra región es el caso María Eugenia Morales Sierra vs. Guatemala, quien alegaba vulneración de derechos respecto a disposiciones del Código Civil de Guatemala que establecía un régimen matrimonial discriminatorio contra la mujer, caso puesto a conocimiento de la Comisión Interamericana de Derechos Humanos. En el caso concreto , María Eugenia Morales Sierra alegaba ante la Comisión Interamericana de Derechos Humanos que la regulación del matrimonio contenido en el Código Civil de Guatemala contenía disposiciones discriminatorias en favor del cónyuge hombre, por lo que, dichas disposiciones vulneraban los mandatos contenidos en la Convención Americana de Derechos Humanos; cuestionándose los artículos 109, 110, 113, 114, 115, 131, 133, 255 y 317 del Código Civil, así el artículo 131 facultaba al esposo para administrar el patrimonio conyugal, el artículo 110 establecía el derecho y la obligación de la mujer de cuidar de los hijos menores y del hogar; el artículo 113 disponía que la mujer casada solo puede ejercer una profesión o tener un empleo cuando ello no perjudique sus funciones de madre y ama de casa, como se puede advertir las disposiciones eran claramente basadas en estereotipos de género.

Así en el caso en comento, la Comisión Interamericana de Derechos Humanos (en adelante CIDD.HH) concluyo: "los artículos impugnados obstaculizan el deber del Estado de proteger a la familia al imponer un régimen que impide que la víctima ejerza sus derechos y cumpla sus responsabilidades dentro del matrimonio en pie de igualdad con su esposo" (2001, numeral. 45). Se reconoce que las disposiciones cuestionadas vulneran el principio de igualdad sustancial pues no concurren criterios objetivos y razonables que sustenten el tratamiento diferenciado y por ende discriminatorio. 
Asimismo, en el numeral $44^{\circ}$, resalta que estos conceptos estereotipados afectan no solo a las mujeres sino también a los hombres "las disposiciones del Código Civil aplican conceptos estereotipados de las funciones de la mujer y del hombre ... y que tienen el efecto ulterior de dificultar la capacidad de los hombres para desarrollar plenamente sus papeles dentro del matrimonio y de la familia ..." (Comisión Interamericana de Derechos Humanos [C.I.DD. $\mathrm{HH}], 2001$, numeral.44).

En el caso Atala Riffo vs. Chile, caso en el cual la ciudadana Atala Riffo por intermedio de la Comisión Interamericana de Derechos Humanos acude a la Corte Interamericana de Derechos Humanos (en adelante la CIDH), alegando un trato discriminatorio por su orientación sexual (lesbiana), y bajo un criterio estereotipado se le quita la tenencia de sus hijas. En este caso, la Corte entre otros aspectos importantes, evidencia y analiza que los órganos jurisdiccionales no están exentos de concepciones estereotipadas al adoptar decisiones. Así, en la sentencia en comento se precisa:

Teniendo en cuenta todo lo anterior, este Tribunal concluye que si bien la sentencia de la Corte Suprema y la decisión de tuición provisoria pretendían la protección del interés superior de las niñas M., V. y R., no se probó que la motivación esgrimida en las decisiones fuera adecuada para alcanzar dicho fin, dado que la Corte Suprema de Justicia y el Juzgado de Menores de Villarrica no comprobaron en el caso concreto que la convivencia de la señora Atala con su pareja afectó de manera negativa el interés superior de las menores de edad (supra párr. 121, 131 y 139) y, por el contrario, utilizaron argumentos abstractos, estereotipados y/o discriminatorios para fundamentar la decisión (supra párr. 118, 119, 125, 130, 140 y 145), por lo que dichas decisiones constituyen un trato discriminatorio en contra de la señora Atala. Por tanto, la Corte declara que el Estado vulneró el derecho a la igualdad consagrado en el artículo 24 en relación con el artículo 1.1. de la Convención Americana, en perjuicio de Karen Atala Riffo. (Corte Interamericana de Derechos Humanos [CIDH], 2012, numeral 146).

En el presente caso, la CIDH concluye que el Estado Chileno incurrió en un acto de discriminación basado en la orientación sexual de la ciudadana Atala Riffo, incumpliendo sus obligaciones de respeto y garantía previstos en la Convención Interamericana de Derechos Humanos, ".En consecuencia, ninguna norma, decisión o práctica de derecho interno, sea por parte de autoridades estatales o por particulares, pueden disminuir o restringir, de modo alguno, los derechos de una persona a partir de su orientación sexual" (CIDH, 2012, numeral. 91) 
Otro caso interesante en cuanto análisis de violencia institucional (Estado) y el impacto diferenciado que produce en el colectivo mujeres, en el cual se analiza el enfoque de género, es la sentencia expedida por la CIDH, caso Miguel Castro Castro vs. Perú, la sentencia fue expedida el año 2006, siendo que los hechos suceden el año 1992, en el marco de un operativo policial de traslado de un grupo de mujeres del centro penitenciario Miguel Castro Castro a otro centro penitenciario; empero, se utilizó gran violencia ( explosivos, armas) conllevando a la muerte de varios internos y gran número de heridos. Lo interesante en este caso, es el análisis que desarrolla la Corte respecto a la violencia ejercida en contra de las mujeres internas y la conceptualización amplia de violencia sexual. Así, en la sentencia referida se precisó la necesidad de un trato diferenciado para mujeres detenidas o arrestadas, no solo al momento de su detención sino también durante el cumplimiento de su sentencia (condiciones de encarcelamiento) justificado por el impacto diferenciado que se ocasiona en ellas, "El Comité para la Eliminación de la Discriminación contra la Mujer ha señalado que dicha discriminación incluye la violencia basada en el sexo, "es decir, la violencia dirigida contra la mujer porque es mujer o que la afecta en forma desproporcionada", y que abarca "actos que infligen daños o sufrimientos de índole física, mental o sexual, ..." (CIDH, 2006,numeral 303). En el caso en comento, la Corte concluyo:

El haber forzado a las internas a permanecer desnudas en el hospital, vigiladas por hombres armados, en el estado precario de salud en que se encontraban, constituyó violencia sexual en los términos antes descritos, que les produjo constante temor ante la posibilidad de que dicha violencia se extremara aún más por parte de los agentes de seguridad, todo lo cual les ocasionó grave sufrimiento psicológico y moral, que se añade al sufrimiento físico que ya estaban padeciendo a causa de sus heridas. Dichos actos de violencia sexual atentaron directamente contra la dignidad de esas mujeres. (CIDH,2006, numeral.308).

Un caso emblemático de violencia de género y estereotipos de género se evidencia en la sentencia expedida por la CIDH, caso González y otras vs. México, más conocido como, Campo Algodonero, en el que se analiza la responsabilidad del Estado Mexicano antes su actuación negligente pese a la desaparición y muerte sistemática de mujeres en la ciudad de Juárez, generalmente mujeres jóvenes pertenecientes a estratos pobres. En esta sentencia, se analiza los prejuicios y estereotipos de las autoridades en su actuación en el caso en concreto. 
Teniendo en cuenta las manifestaciones efectuadas por el Estado es posible asociar la subordinación de la mujer a prácticas basadas en estereotipos de género socialmente dominantes y socialmente persistentes, condiciones que se agravan cuando los estereotipos se reflejan, implícita o explícitamente en políticas y prácticas, particularmente en el razonamiento y el lenguaje de las autoridades de policía judicial, como ocurrió en el presente caso" (CIDH, 2009, numeral 401).

En el sistema convencional Europeo, también se han expedido sentencias que evidencian estereotipos de género que conllevan a situaciones de discriminación; así el Tribunal Europeo de Derechos Humanos, ha emitido sentencias en los que se ha analizado dispositivos legales que contienen estereotipos de género, uno de estos casos emblemáticos es el caso Abdulaziz, Cabales y Balkandali contra Reino Unido, sentencia expedida el 28 de mayo de 1985, caso a que hace referencia Almeida (2009); en el citado caso se cuestionaba un trato discriminatorio entre migrantes mujeres y hombres, pues en el caso de hombres migrantes legales tenían la posibilidad de traer a sus esposas al territorio del Reino Unido bajo el argumento de unidad familiar; sin embargo, ello no era permitido en el caso de migrantes mujeres legales.

En el mencionado caso, el Tribunal Europeo resolvió que efectivamente se produjo un acto de discriminación por razón de sexo (motivo prohibido); no obstante, el análisis parte por la protección de la vida familiar, destacándose que en esta sentencia el Tribunal Europeo enfatiza con mayor incidencia el análisis de protección a la vida familiar para luego derivar que se había producido una discriminación directa. En la referida sentencia, el Tribunal analizaba la importancia de la protección de la unión matrimonial, "lo que quiera que pueda significar la palabra "familia", ese significado debe en cualquier caso, incluir la relación que surge a través de una relación matrimonial" (citado Almeida, 2009, p. 25); en la sentencia en comento, se hacía bastante incidencia en la protección el matrimonio legal.

Como se ha evidenciado, de las sentencias citadas, los estereotipos de género están presentes en las conductas de privados, funcionarios estatales, en la dación de leyes, en su aplicación, y como bien refiere la CIDD.HH en el caso María Eugenia Morales Sierra vs. Guatemala, los estereotipos de género no solo han perjudicado y siguen perjudicando a las mujeres sino también a los hombres encasillándolos en un prototipo que no les ha permitido disfrutar en libertad sus sentimientos, sus derechos como el de la paternidad, al limitar su vinculación afectiva. 
Es por ello, que hoy sehabla denuevas masculinidades problematizando esa negativa masculinidad hegemónica y jerarquizante. Como refiere Faur (2004), tanto mujeres y hombres forman sus identidades influenciadas por las costumbres, instituciones, dispositivos legales; no obstante, cualquier intervención de cambio en estos modelos de masculinidades implica un análisis e intervención no solo individual sino también relacional

Siendo así, la problemática no puede ser visualizado parcialmente enfocándose solo en las mujeres asumiendo que son ellas las que tienen el problema; por el contrario, se necesita una visión más amplia que se oriente al involucramiento del hombre, pues se reitera que los estereotipos de género afectan tanto a mujeres y hombres, aunque con mayor impacto en el colectivo mujeres, y dentro de este grupo en las más vulnerables por razón de edad, educación, pobreza, etc.

Frente a esta situación, el enfoque de género emerge como una herramienta que permite visibilizar situaciones de asimetrías de poder basadas en estereotipos de género equivocados, problematizando la creencia de roles asignados por un supuesto "orden natural", orientándose a lograr una intervención equitativa basada en derechos, teniendo como fin la defensa de la persona humana y hacer efectivo la igualdad sustancial. Así, Mantilla (2013) precisa que:" La aplicación de una perspectiva de género permite observar y entender el impacto diferenciado de programas, proyectos, políticas y normas jurídicas sobre las personas, con el fin de evitar que se reproduzcan situaciones de discriminación y exclusión"(p.134); por ende, constituye una herramienta de análisis para la intervención y abordaje de la problemática que involucra a la mujer y al hombre.

Por ello, el enfoque de género como instrumento de análisis, aunque no el único, permite lograr un equilibrio en las diversas esferas relacionales permitiendo una intervención más equitativa que se oriente a la protección del ser humano y garantice la vigencia de derechos; por tal razón, el enfoque de género no puede ser asociado o identificarse como aquel instrumento en beneficio solo de la mujer; por el contrario, ayuda a la defensa de la persona humana identificando situaciones de inequidad ya sea en agravio de la mujer o el hombre; pues su finalidad es constituir un instrumento que permita que toda intervención ya sea a través de políticas públicas, programas, leyes, decisiones jurisdiccionales se enfoque en la persona humana y la defensa de sus derechos, por ello permite identificar situaciones de vulnerabilidad originadas por prejuicios y estereotipos permitiendo una intervención que permita dotar de un espacio de equidad e igualdad de oportunidades; y si bien, se hace mayor referencia al colectivo 
mujeres ello obedece a que constituyen históricamente un colectivo de mayor vulnerabilidad en contraposición a los hombres.

Sin embargo, las políticas adoptadas por los Estados deben ser transversales, multisectoriales, interseccionales orientadas a la hacer efectivo el principio de igualdad material y la prohibición de discriminación; por ello, admite la necesidad que con dicho fin se adopten acciones afirmativas, no obstante, en estas siempre debe tenerse presente el enfoque de género a efecto de valorar y análisis el impacto que estas medidas tendrán, pues en ocasiones a pesar de diseñar acciones e intervenciones en principios neutras se provoca el efecto adverso. En este sentido, las medidas de acción positiva serían aquellas acciones, normas, planes orientados a favorecer a grupos poblacionales que por razones de edad, sexo, condición se encuentran en situación de desventaja frente a la mayoría de la población; por lo que para lograr superar esa desventaja y logren las mismas oportunidades se admite un trato diferenciado de manera temporal, siempre que exista una causa objetiva y razonable que justifique el tratamiento diferenciado. Así en la Recomendación General 25, el Comité CEDAW, señala:

Hay una diferencia clara entre la finalidad de las "medidas especiales" a las que se hace referencia en el párrafo 1 del artículo 4 y las del párrafo 2. La finalidad del párrafo 1 es acelerar la mejora de la situación de la mujer para lograr su igualdad sustantiva o de facto con el hombre y realizar los cambios estructurales, sociales y culturales necesarios para corregir las formas y consecuencias pasadas y presentes de la discriminación contra la mujer, así como compensarlas. Estas medidas son de carácter temporal. (Comité CEDAW, RG. 25, 1986, numeral 15)

En este camino de reivindicación de derechos e igualdad material hacia las mujeres, es importante enfatizar que el proceso de construcción de identidades e interacciones de género no es estático por el contrario es dinámico, pero ello no implica desconocer que la modificación de estos patrones implica no solo la intervención individual sino que responden a diversas influencias; por ende, la intervención en modificación de estos patrones debe darse en diversos ámbitos, multirelacional, no se puede cambiar la realidad solo con normas.

Por ello, se reitera que enfoque de género constituye una herramienta de análisis importante; "tanto las subjetividades como las relaciones humanas están construidas sobre ideas preconcebidas sobre el sexo, el género y la sexualidad. Estas ideas instauran o refuerzan identidades y prácticas que creemos naturales, pero que obedecen a construcciones sociales y culturales. 
El enfoque de género permite identificar los imaginarios, juicios de valor y conductas que crean y fuerzan diferencias sexuales, y generan relaciones desiguales de poder, así como ejercicio desigual de los derecho" (Defensoría del Pueblo Ecuador, citado por Federación Iberoamericana de Ombusdman, 2018, p. 87); este instrumento, es útil para el diseño y adopción de medidas legislativas y preventivas para hacer frente a la violencia de género, "pone de manifiesto las causas y los efectos relacionados con el género de la violencia. La expresión refuerza aún más la noción de la violencia como problema social más que individual, que exige respuestas integrales, más allá de aquellas relativas a sucesos concretos, autores y víctimas y supervivientes" (Comité CEDAW, Recomendación General 35, 2017, numeral 9), en la citada recomendación se reconoce que la violencia de género contra la mujer se produce en todos los espacios y por ende la necesidad de una intervención relacional, transversal.

Siendo así, y comprendiendo que la discriminación contra la mujer, que incluye la violencia de género, responde a estereotipos culturales y sociales, implica que su abordaje a efecto de lograr una real igualdad sustancial entre hombres y mujeres, parte por reconocer la necesidad de una intervención individual y relacional; por ende, no se puede pretender lograr cambios solo a través de dación de dispositivos legales sino es imperiosa la necesidad de políticas públicas y sociales con enfoque de género que se oriente al plano individual, jurídico y social.

\section{DISYUNTIVAS DE LAS MUJERES Y LA NECESIDAD DE POLÍTICAS SOCIALES CON ENFOQUE DE GÉNERO}

Como se precisó, un punto de inflexión en las relaciones de hombres y mujeres, ha sido la incursión de la mujer en el mercado laboral (formal e informal), así como, el mayor acceso a la educación, aspectos que han impactado en las estructuras familiares, roles familiares y fecundidad; pero también reconocer que las mujeres debido a estos estereotipos de género afrontan mayores niveles de pobreza, de inequidad en el uso de su tiempo, asumen mayores cargas en las labores del hogar como consecuencia de la injusta división sexual del trabajo, mayor dificultad de permanencia en el ámbito laboral, menos acceso a las prestaciones de seguridad social, en definitiva tienen que afrontar constantes disyuntivas.

En este nuevo panorama, de grandes retos no podemos ser ajenos a visualizar estructuras familiares donde las mujeres constituyen cabeza del hogar, por ende, responsables de generar ingresos para la subsistencia de su familia; pero también se advierten hogares en los que tanto el hombre 
como la mujer tienen que laborar para hacer frente a las necesidades de los hijos. Sin embargo, en el caso particular de la mujer pese a laborar sigue asumiendo los roles domésticos de cuidado y crianza de los hijos, esto es, se sigue perpetuando la clásica división sexual del trabajo; por ende, se incrementa las exigencias para las mujeres que en ocasiones se encuentran en la disyuntiva de elegir entre su familia y su desarrollo profesional e independencia económica, repercutiendo en el uso de su tiempo e independencia económica.

Por otro lado, en el caso de mujeres solteras sin carga familiar tienen que lidiar con los patrones culturales que identifican mujer como sinónimo de maternidad o finalidad matrimonial, convivencial; olvidando que en un contexto de libertad es decisión propia de las mujeres no transitar por el sendero de la maternidad sin que dicha decisión las descalifique para la realización de una vida plena y ejercicio de sus derechos. No obstante, tampoco son ajenas a hacer frente a las dificultades en su incursión y permanencia en el mundo laboral a diferencia de los hombres, y en muchos casos con menores salarios, evidenciándose situaciones de inequidad que pueden responder a que estos contextos laborales se han diseñado desde la óptica de la masculinidad, olvidando considerar las necesidades que también las mujeres demandan.

En los supuestos citados, algo es evidente, sea cual fuere el contexto en el que la mujer se desarrolla, siempre se enfrenta a disyuntivas que exigen y la exponen a constantes dilemas; repercutiendo y afectando el ejercicio pleno de sus derechos; en contraposición a los hombres, quienes no se ven expuestos a estos dilemas, pues se asumen que los roles de lo doméstico, maternidad, cuidados es exclusivo de las mujeres; y en algunos casos su involucramiento es mínimo.

Es así, que en este nuevo panorama de incursión dela mujer en elámbito laboral, ya sea formal o informal, no ha conllevado mayor involucramiento del hombre en las labores del hogar, en el reparto de las labores domésticas, coparentabilidad responsable, en concretizar relaciones más democráticas y de respeto de derechos; tampoco se ha diseñado políticas sociales agresivas para hacer frente a la desigualdad de género orientadas a conciliar familia y trabajo con énfasis en la mujer trabajadora informal cabeza de hogar, o en el caso de igualdad de derechos laborales y condiciones de trabajo en el caso de mujeres sin carga familiar.

Ello nos lleva a evidenciar la necesidad del replanteamiento de roles y espacios, de sincerar los avances al respecto; sin que ello implique 
descuidar estrategias que permitan un mayor involucramiento del hombre en las tareas del hogar o en actividades que tradicionalmente eran destinadas a las mujeres.

Frente a este contexto, es preocupante la situación de las mujeres trabajadoras informales con carga familiar o dependencia económica, quienes no cuentan con los beneficios de la seguridad social, con nulo acceso al crédito y a la propiedad, precisamente porque se desarrollan en el ámbito de la informalidad; a ello se suma la falencia del Estado de no ofrecer políticas de cuidado universales a favor de sus hijos, situación que no solo repercute en una situación de mayor vulnerabilidad, sino que también incide en el desarrollo integral de estos niños, niñas y adolescentes perpetuando el círculo de pobreza, violencia y exclusión social, no en vano se habla de la feminización de la pobreza, y muchas de estas mujeres al mantenerse en el ámbito informal no contarán a futuro con las previsiones de la seguridad social (pensiones).

Pero también, las mujeres que se han incorporado al mercado laboral formal presentan dificultades, tienen que lidiar con la disyuntiva del desarrollo profesional y familiar, situación que demanda el auxilio de otra persona, generalmente mujer, para que se encargue de las labores domésticas o decidir dejar de laborar, dado el poco involucramiento del hombre en dichas labores.

Ello gráfica lo difícil de este escenario para las mujeres trabajadoras tanto en el ámbito formal como informal. Siendo que en el ámbito formal el nivel competitivo y de mayor exigencia a la mujer, basado en estereotipos, exige de ella conciliar el trabajo y carga familiar (hijos), por ello, la necesidad de políticas de cuidado que permitan conciliar el trabajo y familia.

Un aspecto importante que surge de estas lógicas relacionales es que las personas contratadas para los cuidados del hogar- trabajo doméstico son en su generalidad mujeres de estratos económicos deprimidos (perpetrándose los estereotipos), y si se recurre a las guarderías se evidencia que los servicios son prestados igualmente por mujeres. Así, Acosta refiere: "Un asunto directamente relacionado con la desigualdad de la ciudadanía de las mujeres, se refleja en el no reconocimiento del valor económico del trabajo doméstico. Esta situación tiene un impacto directo en la vida familiar-Se sigue dando por sentado que las mujeres, despliegan toda su energía en favor de la familia, sin que este aporte tenga valor monetario"(2007, p. 206). Por ello, la necesidad de que la labor 
doméstica sea valorizada, revalorada y la exigencia de una adecuada regulación y especialización del trabajo doméstico sin encasillarse en roles.

Como se evidencia, las mujeres en diversos escenarios y etapas de vida presentan factores de mayor vulnerabilidad, algunas en mayor grado que otras, como aquellas con dependencia económica por falta de oportunidades y que han sido encasilladas al orden doméstico. Esta situación, asignarles como un orden natural las labores del hogar ( ámbito doméstico) conlleva mayor dificultad de conciliar sus tiempos y aspiraciones laborales, dificultando su incursión y permanencia en el mundo laboral con las repercusiones que ello implica, y que tiene mayor impacto en el caso de la mujer trabajadora informal con carga familiar quien al no contar con los beneficios laborales que la formalidad le brinde ni con seguridad social y mucho menos con prestaciones estatales de cuidado o guardería públicas, tiene que delegar el cuidado de sus hijos a un tercero o en el hijo mayor, generalmente un niño o adolescente, incrementándose los riesgos de vulnerabilidad y violencia hacia los niños, niñas y adolescentes.

Este incremento de mujeres a cargo del hogar o familias monoparentales femeninas se evidencia en un estudio efectuado por Ullmann, Maldonado y Otros sobre la Evolución de las estructuras familiares en América Latina 1990-2010 como se detalla en el siguiente cuadro:

\section{Figura $N^{\circ} 01$}

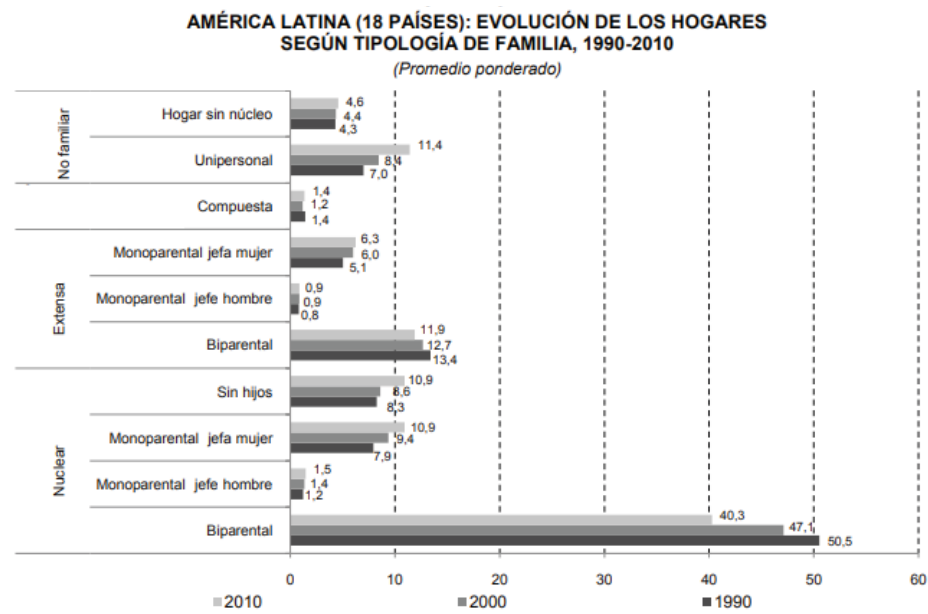

Figura $N^{\circ}$ 1: Fuente CEPAL Evolución de las familias en América Latina 
Esta situación gráfica, evidencia, la vulnerabilidad de este colectivo, y mayor grado de vulnerabilidad de algunos grupos de mujeres frente a otras; por ello la necesidad de políticas sociales con enfoque de género; como por ejemplo, políticas de cuidado universales ofertadas por El Estado, enfocando sus intervenciones en sectores más vulnerables; no con la finalidad de perennizar o incrementar estas asimetrías de roles; por el contrario, lo que se busca es que se permita que las mujeres logren su independencia económica sin tener la disyuntiva de elegir y postergar sus legítimos derechos e intereses de realización personal; como refiere Castelló (2011) "la fuerza de la domesticidad no afecta por igual a todas las mujeres de la estructura social, sino que penetra de forma mucho más abrumadora entre las mujeres de los estratos más bajos, limitando sus posibilidades de elección en la gestión del cuidado, tanto desde la perspectiva material como desde el punto de vista simbólico" (p.38); ello evidencia las inequidades del sistema y evidencia las diversas demandas de las mujeres, pues sus necesidades no son homogéneas.

Por ello, las intervenciones del Estado, no solo deben incidir en lograr mayor independencia económica de la mujer, mejor distribución de recursos, sino también su inclusión en los ámbitos políticos y sociales, a efectos de que representen las necesidades de este colectivo en la toma de decisiones; decisiones que tradicionalmente son diseñadas y adoptadas desde la visión masculina; pues son los hombre los que incursionan en mayor número en los escenarios políticos; es por ello que se justifica la necesidad de las cuotas femeninas en los diversos ámbitos políticos de elección popular.

Frente a este panorama se justifica la necesidad de políticas sociales con enfoque de género que respondan a las necesidades de las mujeres pero que involucren en esta problemática al hombre. Si bien las mujeres han logrado avances en este arduo camino de reivindicación de derechos e igualdad sustancial al lograr mayor acceso a : educación, incursión en el mercado laboral, actividades políticas, etc; aún no se ha superado la clásica división sexual del trabajo basado en estereotipos ni se ha logrado participación política representativa; como refiere Armijo (2018), se sigue manteniendo los cánones masculinos y las mujeres deben adecuarse a ello, por ello no se evidencia sus necesidades en ámbito laboral y familiar; no se ha logrado una redefinición de las instituciones con claro sesgo masculino; ello evidencia la necesidad de políticas públicas y sociales más agresivas con enfoque de género, transversales y interseccionales.

Hacia el 2000, un nuevo enfoque basado en derechos daba las bases de sustentación para el desarrollo de políticas de género. Sin embrago, la 
incorporación de las mujeres a la ciudadanía social suscita un doble problema. Al ser consideradas como ciudadanas, no se produjo al mismo tiempo una redefinición de la visión sexual del trabajo al interior de la familia, no obstante, sus vínculos y responsabilidades familiares. Por otro lado, al incorporar atributos y características masculinas, como la participación en el empleo, se hizo abstracción de las diferencias culturales entre hombres y mujeres. De esta forma los beneficios de la ciudadanía social han incidido de manera diferencial entre hombres y mujeres debido a que las políticas de bienestar se han centrado en las personas que participan en el mercado, reproduciendo las relaciones de subordinación en la esfera familiar. (Arriagada, 2006, p.18)

En este sentido, es necesario seguir trabajando por la igualdad de derechos, en diversos escenarios, como en el ámbito laboral por ejemplo, desde un enfoque de participación democrática en derechos, obligaciones e igualdad en cuanto a las condiciones de trabajo; así por ejemplo; en el caso de las licencias por maternidad se identificaba clásicamente con la mujer; sin embargo, pese a que en nuestro país se ha reconocido la licencia por paternidad esta es otorgada por menos días en comparación con la mujer, situación que no permite un equilibrio y mayor involucramiento del hombre en los roles parentales; por ello un tema interesante sería el trabajo de las licencias laborales basadas en enfoque de género que permitan una mayor democratización de los roles familiares y fomento de la coparentabilidad; ello no implica desconocer los avances que se han logrado pero aún falta mucho camino por recorrer. En este aspecto, sería interesante fomentar incentivos para el otorgamiento de licencias laborales por enfermedad de familiares o necesidades médicas de dependientes incentivando en su dación y ejecución medidas neutras a efecto de que no se asimile como beneficiario solo a mujeres pues ello refuerza las concepciones estereotipadas, un ejemplo en este aspecto, es la dación de La Ley Nro 30119, ley que concede el derecho de licencia al trabajador de la actividad pública y privada para la asistencia médica y la terapia de rehabilitación de personas con discapacidad.

Son estas situaciones que abogan por la necesidad y justificación de políticas diseñadas por el Estado que respondan a esta realidad, políticas con enfoque de género entendiendo esta por redefinir roles; a estos efectos Arraigada (2006), precisa "es necesario trabajar en la construcción de nuevas formas dearticulación entrelas políticas sectoriales tradicionales y los objetivos transversales. En este sentido, los temas de equidad de género comparten, con los de la lucha contra la pobreza, ambientales o de derechos humanos, un carácter transversal e internacional“ (p.14). Pero estas soluciones, como se ya se ha precisado deben involucrar no solo a las mujeres sino también 
a los hombres como parte de la problemática, no se puede solucionar las situaciones de inequidad ni problemas estructurales enfocándose solo en las mujeres, olvidando que los protagonistas del problema son hombres y mujeres y el contexto social.

Sobre el particular resulta interesante un estudio efectuado por Bustelo y Lombardo (2013) sobre los marcos interpretativos de las políticas de igualdad en Europa; en dicho estudio evidencian que un gran problema en la intervención de los Estados a través de sus políticas públicas con enfoque de género es que estas se construyen, diseñan a partir de las diferencias sexuales; por ende, llegan a una conclusión equivocada, pues conceptualizan que la desigualdad es un problema de las mujeres; esta situación conlleva a distorsiones en el abordaje de las diferencias e inequidades basadas en estereotipos y prejudicios de género.

Así pues, a pesar de contar con un instrumento convencional universal y las acciones de los Estados en sus legislaciones internas, formalmente pareciera que se hubiera logrado cambios, pero la realidad es otra, como precisa Noguera (s/f), " Esto nos permite llegar a la conclusión de que a pesar del reconocimiento constitucional y legal de los derechos de la mujer, y su evolución durante los últimos años, no se ha producido una ruptura de la división espacio-genero la cual solo puede concebirse no como un cambio en las personas (hombre o mujer) que ocupa estos espacios sino de sus lógicas relacionales". Ello implica, comprender que la realidad ha impactado en las relaciones interpersonales; por ende, en las estructuras familiares y roles, lo que conlleva a considerar las diversas necesidades que exigen respuesta del Estado y cuya comprensión de la realidad permitirá una intervención adecuada.

Dentro de estas políticas públicas es inexorable la necesidad de políticas de cuidado y especialización con enfoque de género como una de las varias herramientas para la lucha contra la desigualdad de género; políticas que traten de conciliar la vida familiar, laboral de las mujeres, que le den alternativas para su independencia económica; asimismo, la necesidad de que se involucren al hombre como parte del problema, fomentando mayor involucramiento en los espacios familiares, aspectos que son socializados por los movimientos que lideran las nuevas masculinidades que involucre a hombre y mujeres con roles paritarios en las responsabilidades del hogar.

En el caso de las mujeres trabajadoras formales con hijos conlleva la necesidad del involucramientodela pareja en las responsabilidades decuidado, políticas de seguridad social, permisos, licencias paritarias. "La implicación de los hombres en el cuidado puede favorecerse a través de las políticas 
públicas con medidas muy concretas, entre las que destaca el establecimiento de permisos de maternidad y paternidad iguales e intransferibles. Para ello es necesario imaginar un modelo de sociedad de personas sustentadoras/ cuidadoras individuales en igualdad. Este modelo de políticas públicas, y no los parches adheridos al modelo tradicional, es el único que permite a las mujeres no tener que elegir entre vida profesional y vida familiar" (Pazos, $2011,18)$. Esta nueva visión exige una apertura a nuevos desafíos y romper con una visión sesgada de los roles de mujeres y hombres.

En este diseño de políticas de cuidado no solo deben orientarse a responder las necesidades y problemática de las mujeres en el ámbito laboral formal sino principalmente en el informal. Al respecto, Blofield (2014) precisa que en relación a la conciliación de la vida familiar y laboral con fines de lograr una igualdad socioeconómica y de género, entre hombres y mujeres, la intervención del Estado a través de sus políticas pueden tener diverso impacto ya sea positivo o negativo, clasificando estas políticas en: secuenciales, desfamiliarización de los cuidados, regulación de contratación de cuidados provistos de manera remunerada desde el hogar. Este escenario, en nuestro medio, aún no ha sido abordado por nuestro Estado diversificando la oferta universal de cuidados por parte del Estado o regulando la oferta de cuidados en el ámbito privado que permitan ayudar a las disyuntivas constantes que las mujeres enfrentan en su día a día y que permitan consolidar mayor ingreso y permanencia al mercado económico formal.

Es necesario, visibilizar que las mujeres no son un grupo homogéneo; por el contrario no todas tienen las mismas oportunidades ni en la familia, ni en la educación ni en el acceso al mercado laboral-económico; por ello, es necesario problematizar, evidenciar que aún persiste una concepción hegemónica de la masculinidad basada en estereotipos de género en las políticas públicas, leyes, programas, lograr un nuevo diseño de la intervención del Estado donde el enfoque de género constituye una valiosa herramienta, pero que también exige acciones concretas para lograr mayor participación social y política de la mujer en los diversos escenarios de toma de decisiones..

En este camino, en nuestro medio se ha elaborado y aprobado la Política Nacional de Igualdad de Género, aprobada mediante Decreto Supremo $\mathrm{N}^{\circ}$ 008-2019-MINP, que hace énfasis en el abordaje de la discriminación estructural reconociendo que ello ha impactado en el colectivo mujeres impidiéndoles el goce de sus derechos a una vida libre de violencia, a sus derechos a la salud sexual y reproductiva, mayor participación de las mujeres en los espacios de toma de decisiones y en sus derechos económicos y sociales., por ello, se busca un abordaje multisectorial e interseccional; sin 
embargo, toda reforma necesita no solo de políticas claras sino también en correspondencia el sustento económico, capacitación constante en los diversos actores sociales, políticos, públicos y en el ámbito educativo, es un reto muy grande pero ineludible. En este documento, Política Nacional de Igualdad de Género, se establece que:

Las brechas de género existentes (empleo, ingresos, uso del tiempo, participación, entre otras), hacen imprescindible la implementación de una política pública que desde un enfoque multisectorial y de género, aborde las principales causas de la discriminación y la desigualdad que afecta principalmente a las mujeres ... situación que requiere de una decidida intervención desde el Estado para impedir su sistemática reproducción social y transmisión intergeneracional ... La Política Nacional de Igualdad de Género aborda la discriminación estructural contra las mujeres como un problema central en el país, generando desigualdad, limitando el ejercicio de los derechos fundamentales y oportunidades de desarrollo de las mujeres; reproduciéndose socialmente y transmitiéndose de generación en generación a lo largo de la historia del país... (Ministerio de la Mujer y Poblaciones Vulnerables [MIMP]Política Nacional de Igualdad de Género, 2019)

Lo interesante en el diseño de la Política Nacional de Igualdad de Género en adición al enfoque de género es que también toma en cuenta los factores interseccionales para un abordaje en la intervención del Estado.

En definitiva, existe un arduo camino por recorrer, si bien el acceso de la mujer al mercado laboral es una pequeño avance ello no ha significado dismitificar su vinculación con los roles domésticos ni el mayor involucramiento del hombre, aún no se ha logrado estrategias que permitan mayor acceso de las mujeres a la seguridad social, educación, políticas de cuidado en igualdad, redefiniendo roles, mayor disfrute de su tiempo, mayor participación en los espacios políticos de toma de decisiones; pero toda estrategia debe involucrar a las mujeres y hombres, pues la afirmación de que el problema es de la mujer y es ella la que tiene que cambiar es una falacia.

A ello tampoco se puede seguir con la visión de la mujer como una ciudadana de segunda, a quien hay que proteger como si fuera un ser débil, es necesario, un justo equilibrio y tratarla como un sujeto de derecho que tiene mucho que aportar y cuyas necesidades y derechos no han sido escuchados, pues las leyes y las políticas no pueden ser diseñadas desde una óptica homogenizante y excluyente, pero también replantear la visión que se tiene o se quiere dar de las mujeres como seres débiles, que necesitan 
constante protección, idea equivocada, lo que se quiere es que se escuche sus necesidades, mayor participación, mayor independencia económica, mayor oportunidad en el disfrute de sus tiempos, no decidir por ellas bajo la óptica andocéntrica sino escuchar sus necesidades y realidades. Así, el Comité para la Eliminación de la Discriminación contra la Mujer, en la Recomendación General $N^{\circ} 35$, sobre la violencia por razón de género contra la mujer, enfatiza que los Estados no solo deben adoptar medidas legislativas sino también preventivas para hacer frente a las causa de la violencia de género , y en estas debe incentivar la participación de las mujeres "Formular y aplicar medidas eficaces, con la participación activa de todas las partes interesadas, como representantes de organizaciones de mujeres y de grupos marginados de mujeres y niñas, para abordar y erradicar los estereotipos, los prejuicios, las costumbres y las prácticas establecidas en el artículo 5 de la Convención, que consienten o promueven la violencia por razón de género contra la mujer y sustentan la desigualdad estructural entre la mujer y el hombre" (Comité CEDAW, Observación General N 35, 2017, numeral 30). Todos soñamos con una sociedad justa, equitativa, donde la valía y respecto del ser humano no esté supeditado a ser mujer o hombre o a lo que se cree ser hombre o mujer, sino a su dignidad intrínseca, por ello, debemos seguir trabajando en ello desde el ámbito individual y relacional.

\section{CONCLUSIONES}

1. El camino de las mujeres a lo largo de la historia no ha sido fácil, siempre han estado y están en constante lucha para lograr la igualdad material, justicia de género, disfrute de derechos donde la dignidad del ser humano y ejercicio de derechos no esté supeditada a ser hombre o mujer, sino a la simple razón de la condición de "seres humanos".

2. Los estereotipos y roles de género obedecen a construcciones sociales, culturales que parten de la diferenciación en base al sexo para asignar roles y atributos que conllevan a generar situaciones de inequidad.

3. El enfoque de género constituye una herramienta de análisis que permite visibilizar situaciones de asimetrías de poder, a partir del cual permite una intervención equitativa. Sin embargo, esta herramienta no puede ser identificada y asimilada exclusivamente a favor de las mujeres sino que es una herramienta aplicada para la protección y vigencia de derechos independientemente de ser hombre o mujer. 
4. La forma en que se pueda superar estas inequidades de estereotipos de género, estos problemas estructurales, dependerá de la posición del Estado frente a ello, a las políticas públicas y sociales que implementen enfoque de género transversales con factores interseccionales pero que evidencien la heterogeneidad de las mujeres y sus necesidades, incidiendo en los grupos de mujeres con mayor vulnerabilidad como en el caso de mujeres trabajadoras informales con carga familiar; así como, la necesidad de una intervención individual y relacional -jurídico y social.

5. Uno de los grandes retos es adoptar medidas afirmativas que permitan a las mujeres mayor equidad; estas políticas no pueden ser excluyentes sino incluyentes, esto es que involucren al hombre y mujer, como parte del problema y solución, y no se siga bajo la óptica que el problema de desigualdad de género es exclusivamente de las mujeres y bajo tal diseño solo la mujer debe cambiar y no el hombre, aseveración muy alejada de la realidad.

6. Frente a ello una de las acciones urgentes es diseñar intervenciones que diseñen políticas de cuidado con énfasis en las mujeres cabeza de hogar con carga familiar y la socialización del hombre en la corresponsabilidad de las tareas domésticas bajo políticas públicas innovadores y redefinición de roles pero desde la igualdad y no mediante acciones de perpetración de roles de manera sutil, este es el desafío pendiente. Así como fomentar, mayor participación de las mujeres en los espacios políticos y sociales de toma de decisión.

\section{REFERENCIAS}

Acosta, G. (2007). Cambios legislativos en la formación y disolución de familias: una mirada de contexto. Familias y políticas públicas en América Latina: Una historia de desencuentros. Comisión Económica para América Latina y el Caribe, 201-210.

Almeida, S. (2009). El concepto de vida familiar en la Jurisprudencia del Tribunal Europeo de Derechos Humanos. Revista de Derecho y ciencias penales: Ciencias Sociales y Políticas. (12), 23-36. Recuperado de https: / / dialnet.unirioja.es $/$ servlet $/$ articulo?codigo $=3339238$.

Armijo, L. (2018).Las políticas de conciliación de la vida familiar y laboral en España y sus avances en la equidad de género. Revista Interdisciplinaria 
De Estudios De Género De El Colegio De México. DOI: http://dx.doi. org/10.24201/eg.v4i0.183

Arriagada, Irma (2006). Cambios en las políticas sociales: políticas de género y familia. Comisión Económica para América Latina y el Caribe.1-23.

Blofield, M., Martínez,J. (2014). Trabajo, familia y cambios en la política pública en América Latina: equidad, maternalismo y corresponsabilidad. Comisión Económica para América Latina y el Caribe. (114).107-125.

Bustelo. M., Lombardo, E. (2013). Los marcos interpretativos de las políticas de igualdad en Europa: conciliación, violencia y desigualdad de género en la política. Revista Española de Ciencia Política (14) 117-140. Recuperado de http:/ / search.ebscohost.com/login.aspx?direct=true $\& \mathrm{db}=$ edsdoj\&AN=edsdoj.2b8df95012cb4039bfcbdf8bc608e168\&lang $=$ es\&site $=$ eds-live $\&$ scope $=$ site.

Carmona, C. (2018).Los Principales Hitos Jurisprudenciales del Tribunal Europeo de Derechos Humanos en materia de Igualdad de Género. UNED. Teoría y Realidad Constitucional, (42), 311-334. Recuperado de file:/ / C:/Users/pjudicial/Downloads/Dialnet-LosPrincipalesHit osJurisprudencialesDelTribunalEur-6800414\%20(1).pdf

Castelló, L. (2011). Trabajo de cuidado, Género y Clase Social. Sociología del Trabajo. 73, s/n. Recuperado de https://recyt.fecyt.es/index.php/ sociologiatrabajo/article/view/55572

CEDAW (1979). Convención de las Naciones Unidas para la eliminación de todas las formas de discriminación contra la mujer. Recuperado dehttp:// www.hchr.org.mx/documentos/CEDAW\%20Final.pdf.

Convención Interamericana para prevenir, sancionar y erradicar la violencia contra la mujer (1994). Recuperado de https://www.oas.org/ juridico/spanish/tratados/a-61.html

Comisión Interamericana de Derechos Humanos (2001). Informe 4/01 María Eugenia Morales de Sierra y Guatemala. Recuperado en https://www.cidh.oas.org/annualrep/2000sp/CapituloIII/Fondo/ Guatemala11.625.htm

Comité para la eliminación de la discriminación contra la mujer. (1986). Recomendación General $\mathrm{N}^{\circ} 25$ Medidas especiales de 
carácter temporal. Recuperado de https://www.refworld.org.es/ publisher,CEDAW,GENERAL,52d905144,0.html

Comité para la eliminación de la discriminación contra la mujer. (1992). Recomendación General No 19 La Violencia contra la Mujer. Recuperado de https://tbinternet.ohchr.org/Treaties/CEDAW/Shared\%20 Documents/1_Global/INT_CEDAW_GEC_3731_S.pdf

Comité para la eliminación de la discriminación contra la mujer. (2010). Recomendación General $N^{\circ} 28$ Proyecto de Recomendación general $N^{\circ} 28$ relativa al artículo 2 de la Convención sobre la eliminación de todas las formas de discriminación contra la mujer. Recuperado de https:/ / www.acnur. org/fileadmin/Documentos/BDL/2012/8338.pdf?file=fileadmin/ Documentos/BDL/2012/8338

Comité para la eliminación de la discriminación contra la mujer. (2015). Recomendación General $N^{\circ} 33$ sobre el acceso de las mujeres a la justicia. Recuperado de https://www.acnur.org/fileadmin/Documentos/ BDL/2016/10710.pdf

Comité para la eliminación de la discriminación contra la mujer. (2017). Recomendación General $N^{\circ} 35$ sobre la violencia por razón de género contra la mujer Recuperado de https://www.acnur.org/fileadmin/ Documentos/BDL/2017/11405.pdf

Cook, R., Cusak, S. (1997). Estereotipos de Género. Perspectivas Legales. Traducido por Parra. A. Profamilia. Recuperado de http://www. profamilia.org.com.

Corte Interamericana de Derechos Humanos. (2006). Sentencia Miguel Castro Castro vs. Perú. Recuperado de https: / /www.corteidh.or.cr/ docs/casos/articulos/seriec_160_esp.pdf

Corte Interamericana de Derechos Humanos. (2009). Sentencia González y otras vs. México. Recuperado de https:/ / www.corteidh.or.cr/docs/ casos/articulos/seriec_205_esp.pdf.

Corte Interamericana de Derechos Humanos. (2012). Sentencia Atala Riffo vs. Chile. Recuperado de https:/ / corteidh.or.cr/docs/casos/articulos/ seriec_239_esp.pdf 
Decreto Supremo No 008-2019-MINP (01 de abril 2019). Política Nacional de Igualdad de Género. Recuperado de https://www.gob.pe/ institucion/mimp/normas-legales/271118-008-2019-MIMP.

Duarte, J. García, J. (2016). Igualdad, Equidad de Género y Feminismo, una mirada histórica a la conquista de los derechos de las mujeres. Revista CS, 18. Recuperado de https://www.redalyc.org/ jatsRepo/4763/476350095006/html/index.htmlDOI:10.18046/recs. i18.1960

Federación Interamericana del Ombusdman (2018). Capacitación en igualdad de género y Derechos Humanos: guía metodológica. PROFIO. Recuperado de https:/ / pradpi.es/publicaciones_fio_giz/Capacitacion_Igualdad_ Genero_DDHH_Guia_Metodologica_teorica.pdf

Faur, E. (2004). Masculinidades y Desarrollo Social. Las relaciones de género desde la perspectiva de los hombres. Recuperado de https: / / www.unicef.org / masculinidades.pdf

Noguera, A. (s.f). Los feminismos y la división espacio-género- VII Congreso virtual sobre Historia de Las Mujeres. Universitat de València. 622-641. Recuperado de https://dialnet.unirioja.es/servlet/ articulo? codigo $=5346956$

Mantilla, J. (2013). La importancia de la aplicación del enfoque de género al derecho: asumiendo nuevos retos. Thèmis (63), 131-146.

Pazos, M. (2011). Roles de Género y Políticas Públicas. En Revista Sociología del Trabajo. Recuperado de https://recyt.fecyt.es/index.php/ sociologiatrabajo/article/view/55571

Rábago, M. (2008). Los conceptos de esfera pública y privada en el "Derecho de Familia". En Cruz, J., Vásquez, R. (coordinadores). Mujeres, familia y trabajo. México D.F: Suprema Corte de Justicia de la Nación y Editorial Fontamara, pp. 1-26.

Ullmann, H., Maldonado, C., Nieves, M. (2014). La evolución de las estructuras familiares en América Latina, 1990-2010. Los retos de la pobreza, la vulnerabilidad y el cuidado. CEPAL

Fecha de recepción: 07-09-2020

Fecha de aceptación: 21-10-2020 